\title{
Halogen light versus LED for bracket bonding: Shear bond strength
}

\author{
Paulo Eduardo Guedes Carvalho1, Valdemir Muzulon dos Santos², Hassan Isber², Flávio Augusto Cotrim-Ferreira ${ }^{1}$
}

Introduction: LED light-curing devices seek to provide a cold light activator which allows protocols of material polymerization with shorter duration. Objective: The present study aimed to evaluate the shear bond strength of bracket bonding using three types of light-curing devices: One with halogen light (Optilight Plus - Gnatus) and two with LEDs (Optilight CL - Gnatus and Elipar Freelight - 3M/ESPE). Results: Comparing the results by analysis of variance, the Gnatus LED device showed an inferior statistical behavior in relation to other light sources, when activated by a short time. But, when it was used for 40 seconds, the polymerization results were consistent with the other evaluated sources. The device with the best average performance was the halogen light, followed by the 3M/ESPE LED. Conclusion: It was concluded that the LEDs may be indicated in orthodontic practice, as long as a protocol is used for the application of light with the activation time of 40 seconds.

Keywords: Orthodontics. Shear bond strength. Orthodontic brackets. Dental bonding.

Introdução: os aparelhos de fotopolimerização por LED buscam proporcionar uma luz ativadora fria, que possibilite protocolos de polimerização do material com menor tempo de duração. Objetivo: avaliar a resistência à tração da colagem de braquetes, utilizando três tipos de aparelhos fotoativadores: um de luz halógena (Optilight Plus - Gnatus) e outros dois de LED (Optilight CL - Gnatus; e Elipar Freelight - 3M/Espe). Resultados: comparando os resultados por meio da análise de variância, o aparelho de LED Gnatus apresentou comportamento estatístico inferior em relação às outras fontes de luz, quando ativado por tempo reduzido. Já quando foi utilizado o tempo de 40 segundos, os resultados de polimerização foram compatíveis com as demais fontes avaliadas. O aparelho que apresentou melhor desempenho médio foi o de luz halógena, seguido pelo LED 3M/Espe. Conclusão: concluiu-se que os LEDs podem ser indicados na prática ortodôntica, uma vez que seja utilizado um protocolo de aplicação da luz com tempo de ativação de 40 segundos.

Palavras-chave: Ortodontia. Resistência à tração. Braquetes ortodônticos. Colagem dentária.

${ }^{1}$ Professor of the MSc course in Orthodontics, University of São Paulo City (UNICID).

${ }^{2} \mathrm{MSc}$ in Orthodontics, University of São Paulo City (UNICID).
How to cite this article: Carvalho PEG, Santos VM, Isber H, Cotrim-Ferreira FA. Halogen light versus LED for bracket bonding: shear bond strength. Dental Press J Orthod. 2013 Jan-Feb;18(1):31.e1-6.

Submitted: August 28, 2008 - Revised and accepted: November 25, 2008

" The authors report no commercial, proprietary or financial interest in the products or companies described in this article.

Contact address: Paulo Eduardo Guedes Carvalho

Rua Cesário Galeno, 483, Tatuapé - CEP: 03.071-000 - São Paulo / SP - Brazil E-mail: paulo@carvalho-ortodontia.com.br 


\section{INTRODUCTION}

In order to facilitate and improve the process of bracket bonding, researches are often conducted with the halogen light, which is the one most used by professionals so far. The device with halogen light source uses a broad spectrum of wavelengths, which has between 400 and $500 \mathrm{~nm}$, and also a light filter that disregards the waves, which do not sensitize the activator commonly used, camphorquinone. Thus, this makes the band of light narrower usable for the resin polymerization. ${ }^{14}$

It is known that the quality of the resin polymerization is represented by the number of double carbon bonds of the methacrylate groups, which have reacted during the resin polymerization. ${ }^{12,15}$ The best time of application of the halogen light is 40 seconds, shown by several studies with this equipment. ${ }^{5,10,17,18}$

Atmadja and Bryant ${ }^{2}$ carried out a study evaluating the microhardness of four resins (P 30, Prisma-Fil, Heliomolar and Durafil). Test specimens were fabricated in cylindrical matrices with $4 \mathrm{~mm}$ in diameter and thickness ranging from 1 to $6 \mathrm{~mm}$. The polymerizing device used was Heliomat and it was activated in three different exposure times (20, 40 and 60 seconds). They concluded that: a) for each type of resin evaluated, the microhardness values decreased with the increasing depth of polymerization, $b$ ) the most effective exposure time was 40 seconds, c) reducing the thickness is the most correct way to achieve proper curing and it is better than to increase the exposure time, d) the light-cured resins continue their polymerization reaction after the light source is removed.

Light intensity is another important factor for preservation of the margins of the resin applied and polymerized. ${ }^{10,18}$ The resins have superior physical properties and better marginal integrity when polymerized by the gradual technique when compared with polymerization initiated with maximum intensity. ${ }^{11}$

Although there are few studies in the literature, it is believed that the LED device has real conditions of replacing halogen devices in offices ${ }^{1,6}$ because it has a cost similar to the halogen lamp and it is much lower when compared to argon laser and xenon plasma arc curing light. Either ways, it is known that LEDs have cold light emitted by a semiconductor, allowing an unlimited period of its use, with a low light spectrum between 460 and $480 \mathrm{~nm}^{7}$ Since camphorquinone, the photo-initiator most used in resin, works absorbing visible light raging 350 to $550 \mathrm{~nm}$ with a peak absorption around $470 \mathrm{~nm}$, the values emitted by the LED seem to be favorable. The ideal light length for composite polymerization should range around $450 \mathrm{~nm}$ and $470 \mathrm{~nm} .{ }^{9}, 16$ These data create the expectation of an optimal polymerization reaction, compensating the lower intensity of light produced by these units, besides generating a reduced heat emission. ${ }^{7}$

The light-curing devices with halogen lamps have a vast literature on the subject, unlike LEDs, which are currently being investigated more intensely. With this in mind, this work aimed to study the shear bond strength of orthodontic brackets, bonded to human teeth, using different resin lightcuring protocols, according to the variation of the light type and light-activation time.

\section{MATERIAL AND METHODS}

This experiment was submitted to the Ethics Committee in Research of the University where it was held, having been fully approved.

For this study the following equipment were compared:

" Light source based on halogen lamp with $600 \mathrm{~mW} / \mathrm{cm}^{2}$ - Optilight Plus device (Gnatus Medical Dental Equipment Ltda, Ribeirão Preto - SP, Brazil).

» Light source based on LED with $700 \mathrm{~mW} / \mathrm{cm}^{2}$ LED device Optilight CL (Gnatus Medical Dental Equipment Ltda, Ribeirão Preto - SP, Brazil).

» Light source based on LED with $1000 \mathrm{~mW} / \mathrm{cm}^{2}$ - Elipar Freelight LED device (3M/ESPE Dental Products, Monrovia - CA, USA).

Fifty premolar teeth that were previously selected were used, teeth with fractures, cracks, fissures, or which had not a perfect facial surface were refused. This sample was divided randomly into five groups with ten teeth each, always kept in saline solution.

The samples were prepared by a dentist with clinical experience in orthodontics and in bracket bonding, not needing help from other operators in the experiment, in order to minimize the possibilities of inter-operator errors. The buccal surfaces of the teeth were first cleaned and polished with rubber cup and pumice for 20 seconds each, at low speed and then washed with water.

The teeth had their buccal surface subjected to application of $37 \%$ phosphoric acid for 20 seconds, then 
washed with water for 20 seconds and dried with compressed air. For the bonding procedure, a specific caliper for bracket bonding and a light-cured orthodontic adhesive system were used - Transbond ${ }^{\mathrm{TM}}$ XT (3M/Unitek, Dental Products, Monrovia - CA, USA). This adhesive was applied on the base of each of the fifty Unitek "full-size" brackets used in this study (3M/Unitek, Dental Products, Monrovia - CA, USA). With the aid of a microbrush, liquid adhesive was applied, from the same adhesive system, onto the etched surface of the tooth. Then, the set bracket / resin was positioned in the center of the clinical crown of the tooth, performing a light pressure with the explorer probe in search of excess material. This material was removed with the tip of this probe in order to prevent the resin covering the bracket base, thereby increasing its retention and, consequently, influencing the results.

From this moment, the polymerization of the specimens was initiated, according to the time set for each of the groups, divided as follows:

"Group 1: Application of halogen light for $40 \mathrm{sec}-$ onds on each bracket (control group).

" Group 2: Application of LED light with the 3M/ESPE device for 40 seconds on each bracket.

"Group 3: Application of LED light with the $3 \mathrm{M} / \mathrm{ESPE}$ device for 10 seconds on each bracket.

" Group 4: Application of LED light with the Gnatus device for 40 seconds on each bracket.

" Group 5: Application of LED light with the Gnatus device for 10 seconds on each bracket.

After carrying out the light-curing of all specimens, as each studied protocol, the set tooth / bracket was placed in plastic matrices that received acrylic resin, in order to create the structure of the specimens (Fig 1).

It was decided to bond the brackets first, followed by the stabilization of the set in the plastic matrix and the inclusion of the resin. This avoided the instability in positioning the tooth during the insertion of the resin. Care was taken so the specimens were perpendicular to the hook that was used for traction, which accurately fit the bracket wings, reducing the opportunities for leverage and unequal traction movements during the test.

The samples were conditioned in moist environment (saline) at a temperature of $37{ }^{\circ} \mathrm{C}$ in the dark, for 24 hours. Then they were taken to the Plastics and
Rubbers Laboratory, in the Chemistry Division at the Institute of Technological Research of São Paulo - IPT, where the tests were performed.

The specimens were subjected to tensile testing by a universal testing machine (EMIC 10,000), with a speed of $1.0 \mathrm{~mm} / \mathrm{min}$ and with a load cell $50 \mathrm{kgf}$. To perform the tests an extractor clutch was used made at the Metal Laboratory in the Engineering Division of the IPT. This clutch fitted the wing of the brackets perpendicular to the specimen, and subsequently fixed on top of the traction machine EMIC (Fig 2).

Each specimen underwent the tensile test and for each moment of bracket bonding rupture a certain value was recorded. These values referred to the load supported by the bracket at the exact moment of rupture. The tests were performed in all 50 teeth in the same day. Statistical tests were used to validate the results and comparison of the groups, the analysis of variance (ANOVA) was used, with significance level of 5\%, followed by Tukey test when differences were found.

\section{RESULTS}

It was intended to arrive to some conclusions from the resin resistance measurements that were made, considering five types of light curing protocols. To study the comparisons between the groups, since the measured data followed approximately normal distributions, the analysis of variance was chosen when comparing the statistical similarity of the five groups.

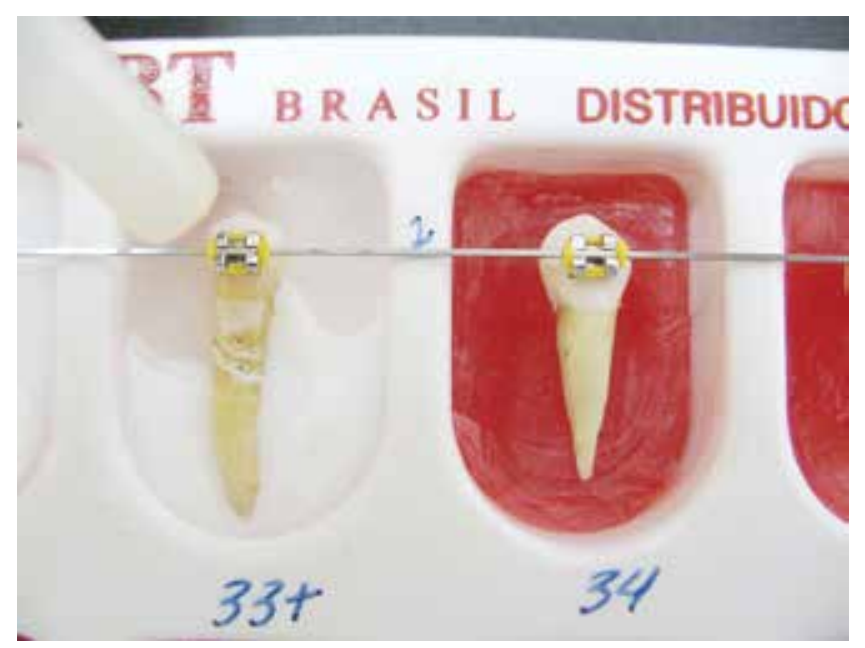

Figure 1 - Tooth / bracket set fixation to the plastic matrix. 


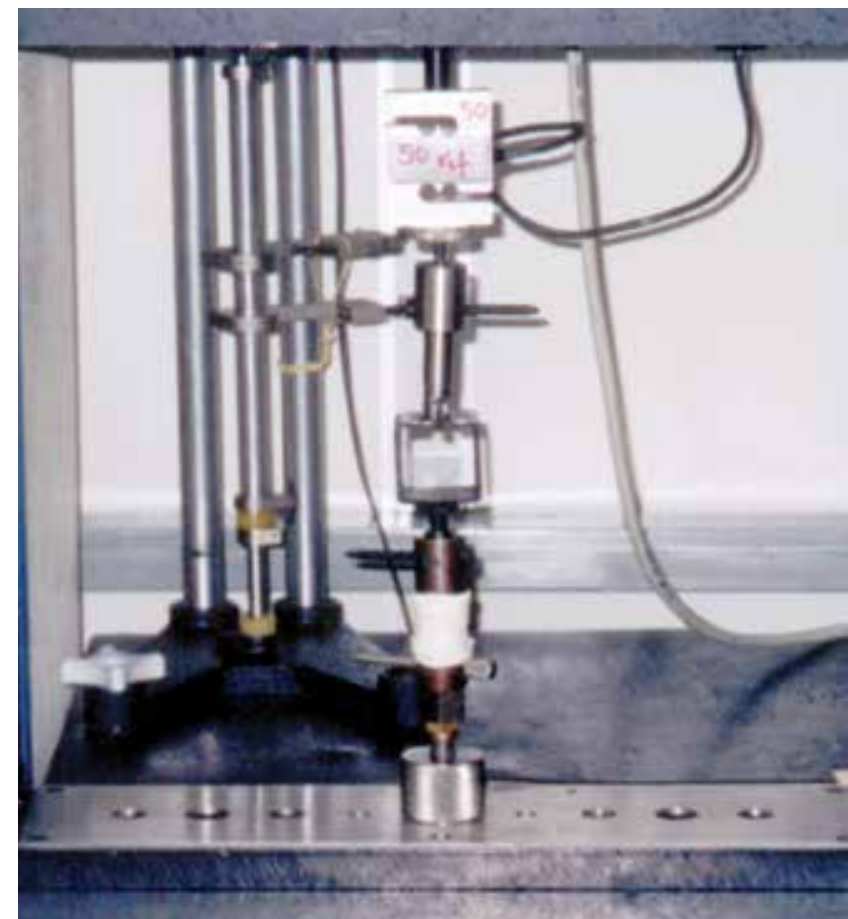

Figure 2 - EMIC 10,000 traction machine.

For this study, first the means and standard deviations were calculated for the measurements studied, and from these results, the analysis of variance test was applied. Since a significant difference in the analysis of variance was found for the total sample, the Tukey test was applied, when comparing the groups, indicating sufficient differences to represent statistical significance between which protocols.

Table 1 presents the mean values and standard deviations for the many light-curing protocols studied. The values obtained on analysis of variance and Tukey's test for comparisons of various measurements, are shown in Table 2.

To facilitate the comparison of data here obtained with the ones in literature, Table 3 presents the mean values of each sample also converted to values of pressure in mega Pascal (MPa), verified from base measurements of the brackets used. The "full-size" brackets have their base with $0.399 \times 0.335 \mathrm{~cm}$, generating a base area of $0.133665 \mathrm{~cm}^{2}$. The values in $\mathrm{MPa}$ are of great importance when interpreting the data on other works, because they eliminate the variation in the size of the different brackets used.

\section{DISCUSSION}

The purpose of researching the LEDs is related to its recent availability in the market, and there is a large number of scientific studies proving its real efficiency. Since the band of light emitted by the LEDs matches the absorption peak of camphorquinone, it creates a great expectation of the polymerization reaction, compensating the reduced intensity of light produced by these units, besides generating a low heat emission.

Once the braces are bonded in the intraoral environment, it receives force applications due to mastication and also by biomechanic forces itself. Various types of force will be acting at this time such as traction, shear and torsion forces, which can act in isolated or combined ways. This work uses tensile forces because it is a force also used in Orthodontics and less studied.

Table 1 - Mean values and standard deviations of the five groups studied, in kgf.

\begin{tabular}{cccccc}
\hline Light-curing & Halogen & \multicolumn{2}{c}{ 3M LED } & \multicolumn{2}{c}{ Gnatus LED } \\
\cline { 2 - 6 } protocol & $\mathbf{4 0 \mathrm { s }}$ & $\mathbf{4 0 \mathrm { s }}$ & $\mathbf{1 0 ~} \mathrm{s}$ & $\mathbf{4 0 ~ \mathbf { ~ }}$ & $\mathbf{1 0 ~ \mathbf { ~ }}$ \\
Group & 1 & 2 & 3 & 4 & 5 \\
Mean & 6.21 & 6.01 & 4.99 & 5.53 & 3.85 \\
SD & 1.74 & 1.34 & 1.00 & 2.28 & 1.05 \\
\hline
\end{tabular}

SD = Standard Deviation; $\mathrm{s}=$ seconds.

Table 2 - Statistical tests for analysis of variance and of Tukey.

\begin{tabular}{cccc}
\hline \multicolumn{2}{c}{ Compared groups } & $\begin{array}{c}\text { Mean } \\
\text { differences }\end{array}$ & Sig. \\
& 3M LED 40 s (G2) & 0.20 & N.S. \\
Halogen light 40 s (G1) & 3M LED 10 s (G3) & 1.22 & N.S. \\
\cline { 2 - 4 } & Gnatus LED 40 s (G4) & 0.68 & N.S. \\
& Gnatus LED 10 s (G5) & 2.36 & 0.05 \\
\hline 3M LED & 3M LED 10 s (G3) & 1.02 & N.S. \\
\hline 3M LED & Gnatus LED 40 s (G4) & 0.48 & N.S. \\
\hline 10 s (G3) & Gnatus LED 10 s (G5) & 2.16 & 0.05 \\
\hline Gnatus LED 40 s (G4) & Gnatus LED 40 s (G4) & -0.54 & N.S. \\
\hline & Gnatus LED 10 s (G5) & 1.97 & 0.05 \\
\hline
\end{tabular}

Minimum Significant Difference $(M S D)=1.9136$; NS = non-significant.

Table 3 - Mean values from the five assessed groups, in MPa.

\begin{tabular}{cccccc}
\hline Light-curing & Halogen & \multicolumn{2}{c}{ 3M LED } & \multicolumn{2}{c}{ Gnatus LED } \\
\cline { 2 - 6 } protocol & $\mathbf{4 0 \mathrm { s }}$ & $\mathbf{4 0 \mathrm { s }}$ & $\mathbf{1 0 \mathrm { s }}$ & $\mathbf{4 0 \mathrm { s }}$ & $\mathbf{1 0 \mathrm { s }}$ \\
Group & 1 & 2 & 3 & 4 & 5 \\
Mean & 4.56 & 4.41 & 3.66 & 4.06 & 2.82 \\
\hline
\end{tabular}


However, it must be emphasized that at the time of the laboratory force application by the stress machine, there is no possibility of obtaining a pure tensile force, but a dominant force with tensile stress and shear forces, secondarily present. Thus the test may provide more complex rupture patterns, involving several types of forces on a single moment. ${ }^{13}$ This factor may be present in most of the studies presented in the literature and be a variant of influence in the absolute comparison of results between the various others displayed.

The objective of this study was to permeate five polymerization time protocols in orthodontics without worrying about the protocols recommended in works of the dentistry area, recommending as viable times of $40 \mathrm{~s}$ and $60 \mathrm{~s}$ to use LEDs. ${ }^{8}$ Different measurement units were used ( $\mathrm{MPa}$ and kgf) only in order to provide a comparative parameter with previous works.

In analyzing the results obtained by analysis of variance, four groups were statistically similar to each other, where only the group 5 (LED Gnatus 10 s) was significantly different. This work showed higher values for the halogen lamp when compared with the other four groups of LEDs. Analyzing the groups, which had the highest light incidence values, it is observed that they possess the best results. These groups, halogen (6.21 kgf), 3M LED $40 \mathrm{~s}$ and $20 \mathrm{~s}$ (6.01 kgf and $4.99 \mathrm{kgf})$ and Gnatus LED $40 \mathrm{~s}$ and $20 \mathrm{~s}$ ( $5.53 \mathrm{kgf}$ and $3.85 \mathrm{kgf}$ ) tend to conclude that the greater the exposure time, the greater the enhancement in retention of the bracket onto the tooth. As comparison to this shear bonding brackets, similar mean values of halogen light $x$ LED were found. ${ }^{3,4,5,15}$
In this study values in MPa and kgf were obtained for the activation time of 40 seconds, which show agreement with the findings of Silva, ${ }^{15}$ who used types of devices compatible with this work, however only evaluating longer light-curing protocols (40 to 60 seconds). It is worth noting that few works are available in the literature studying shear bond strength of brackets, especially with proposals for shorter curing time (less than 20 seconds) and that it should always be taken into account the methodology, forms and types of brackets extractors, controllable and uncontrollable variations, and the number of people involved.

\section{CONCLUSIONS}

Based on the methodology applied in this study, and according to the results obtained and applied to the statistical analysis, it was considered reasonable to conclude that:

" The halogen lamp provided the highest mean shear bond strength of brackets, but without statistical significance in relation to three other protocols performed with LED devices.

" The 3M/ESPE LED device had shear bond strength of brackets similar to that obtained by halogen source, even with the protocol with 10 seconds of activation.

" The Gnatus LED device showed shear bond strength of brackets similar to the one obtained by halogen source, only with the activation protocol of 40 seconds, being significantly lower when used for 10 seconds. 


\section{REFERENCES}

1. Asmussen E, Peutzfeldt A. Light emitting diode curing: influence on selected properties of resin composites. Quintessence Int. 2003;34(1):71-5

2. Atmadja G, Bryant RW. Some factors influencing the depth of cure of visible light-activated composite resin. Aust Dent J. 1990;35(3):213-8.

3. Bengtson NG, Bengtson AL, Carvalho DS, Rossetto SM. Estudo comparativo da força adesiva de quatro materiais para colagem de braquetes. Rev Dental Press Ortod Ortop Facial. 2003:8(3):43-7.

4. Bishara SE, Ajlouni R, Oonsombat C. Evaluation of a new curing light on the shear bond strength of orthodontic brackets. Angle Orthod. 2003:73(4):431-5.

5. Carillo VEB. Estudo comparativo in vitro da capacidade adesiva da resina fotoativada pela luz halógena e por laser de argônio, utilizando-se bracketes metálicos em pré-molares humanos [tese]. São Paulo (SP): Universidade de São Paulo; 2004

6. Fujibayashi K, Norihiko M, Masaaki O, Hirokazu I, Atsushi K. Newly developed curing unit using blue light emitting diodes. Dent Japan. 1998;34(1):49-53.

7. Kurachi C, Eduardo CP, Magalhães DV, Bagnato VS. Human teeth exposed to argon laser irradiation: determination of power-timetemperature working conditions. J Clin Laser Med Surg. 1999;17(6):255-9.

8. Kurachi C. Estudo comparativo do laser, do led azul e da lâmpada convencional no processo de polimerização da resina composta dental [dissertação]. São Carlos (SP): Universidade de São Paulo; 2000

9. Leonard DL, Charlton DG, Roberts HW, Cohen ME. Polymerization efficiency of led curing lights. J Esthet Restor Dent. 2002;14(5):286-95.
10. Mehl A, Hickel R, Kunzelmann KH. Physical properties and gap formation of light-cured composites with and without soft start-polymerization. J Dent. 1997:25(3-4):321-30.

11. Mills RW, Jandt KD, Ashworth SH. Dental composite depth of cure with halogen and blue light emitting diode technology. Brit Dent. 1999:186(8):388-91.

12. Peutzfeldt A. Correlation between recordings obtained with a lightintensity tester and degree of conversion of curing resin. Scand J Dent Rest. 1994;102(1):73-5.

13. Phillips RW. Materiais dentários de Skinner. 8a ed. Rio de Janeiro: Interamericana; 1984

14. Santos LA, Turbino ML, Youssef MN, Matson E. Microdureza de resinas compostas: efeito de aparelhos e tempos de polimerização em diferentes profundidades. Pesq Odontol Bras. 2000:14:65-70.

15. Silva PCG. Estudo in vitro da colagem de braquetes sobre o esmalte dental humano: utilizando leds como fonte de luz - análise comparativa com a luz halógena [tese]. Araraquara (SP): Universidade Estadual Paulista; 2003.

16. Teshima W, Nomura Y, Tanaka N, Urabe H, Okazaki M, Nahara Y. ESR study of camphorquinone/amine photoinitiator systems using blue lightemitting diodes. Biomaterials. 2003 May:24(12):2097-103.

17. Turbino ML, Vinha D, Centola AL, Campos GM. Photopolymerized resins surface hardness variation in relation to time of polymerization and setting. Braz Dent J. 1993;3(2):87-94

18. Uno S, Asmussen E. Marginal adaptation of a restorative resin polymerized at reduced rate. Scand J Dent Res. 1991;99(1):440-4. 